\title{
QUALITY IMPROVEMENT Sustainability in quality improvement: redefining value
}

\author{
Authors: Frances Mortimer, ${ }^{\mathrm{A}}$ Jennifer Isherwood, ${ }^{\mathrm{B}}$ Alexander Wilkinson ${ }^{\mathrm{C}}$ and Emma Vaux ${ }^{\mathrm{D}, \mathrm{E}}$
}

Sustainability can be considered a domain of quality in healthcare, extending the responsibility of health services to patients not just of today but of the future. The longer term perspective highlights the impacts of our healthcare system on our environment and communities and in turn back onto population health. A sustainable approach will therefore expand the healthcare definition of value to measure health outcomes against environmental and social impacts alongside financial costs. We set out a practical framework for including these new dimensions in an already well-defined model of quality improvement. This has the potential to harness the growing quality improvement movement to shape a more sustainable health service, while improving patient outcomes. Early experience suggests that the new model may also provide immediate benefits, including additional motivation for clinicians to engage in quality improvement, directing their efforts towards high value interventions and enabling capture and communication of a wider range of impacts on patients, staff and communities.

KEYWORDS: Sustainability, quality improvement, value, social value, environment

\section{Sustainability as a domain of quality in healthcare}

The Royal College of Physicians (RCP) expanded on the Institute of Medicine's six domains of quality to include sustainability (Fig 1). ${ }^{1}$ The RCP recognised sustainability to be 'a characteristic of healthcare which must run through and moderate other domains' and stated that 'healthcare should be considered not only in terms of what can be delivered to an individual today, but also to the population in general and the patients of the future. ${ }^{2}$

Sustainability, as coined by the RCP, refers to the capacity of a health service to deliver healthcare over time, with consideration to future generations. With the increasing demand on the health

Authors: ${ }^{\text {A }}$ medical director, Centre for Sustainable Healthcare, Oxford, UK; ${ }^{\text {B }}$ Clinical fellow in sustainability, Royal College of Physicians, London, UK; ${ }^{C}$ consultant in respiratory medicine, East

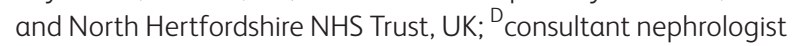
and general physician, Royal Berkshire NHS Foundation Trust, UK; $\mathrm{E}_{\text {senior censor and vice president education and training, Royal }}$ College of Physicians, London UK

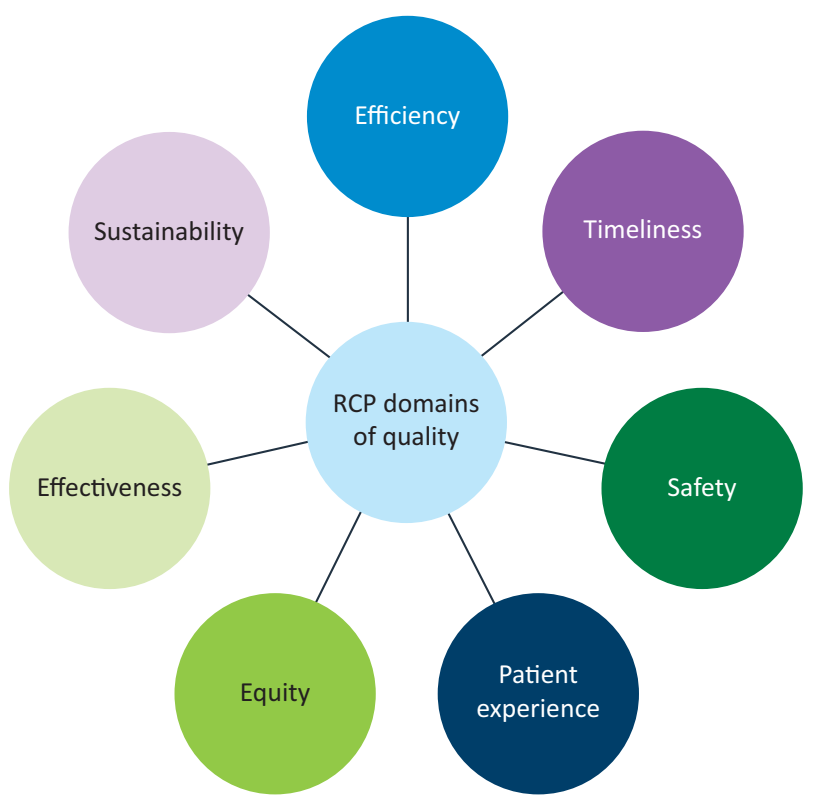

Fig 1. Domains of quality (adapted by the Royal College of Physicians from the Institute of Medicine). ${ }^{1}$

service and an already large financial deficit, the major threat to health service sustainability is most often identified as financial. However, healthcare, as with all human activity, takes place within a social and environmental context, not just an economic one. Important social and environmental constraints exist alongside the well-publicised financial restrictions. These include declining family support for an ageing population and the legal requirement to reduce greenhouse gas emissions by $80 \%$ in line with the UK Climate Change Act 2008. In order for the NHS to survive, it must be able to anticipate and respond to changes across all three spheres.

Arguably, the health service has a responsibility to go beyond safeguarding its own sustainability and should contribute to the sustainability of wider society. There is increasing recognition that individual and population health depends on functioning ecosystems, strong social networks and economic opportunity even more than access to good healthcare. ${ }^{3,4}$ This has prompted a debate on the role of the medical profession in influencing policy relating to these wider social determinants of health, ${ }^{5}$ which include education, employment and political empowerment as 


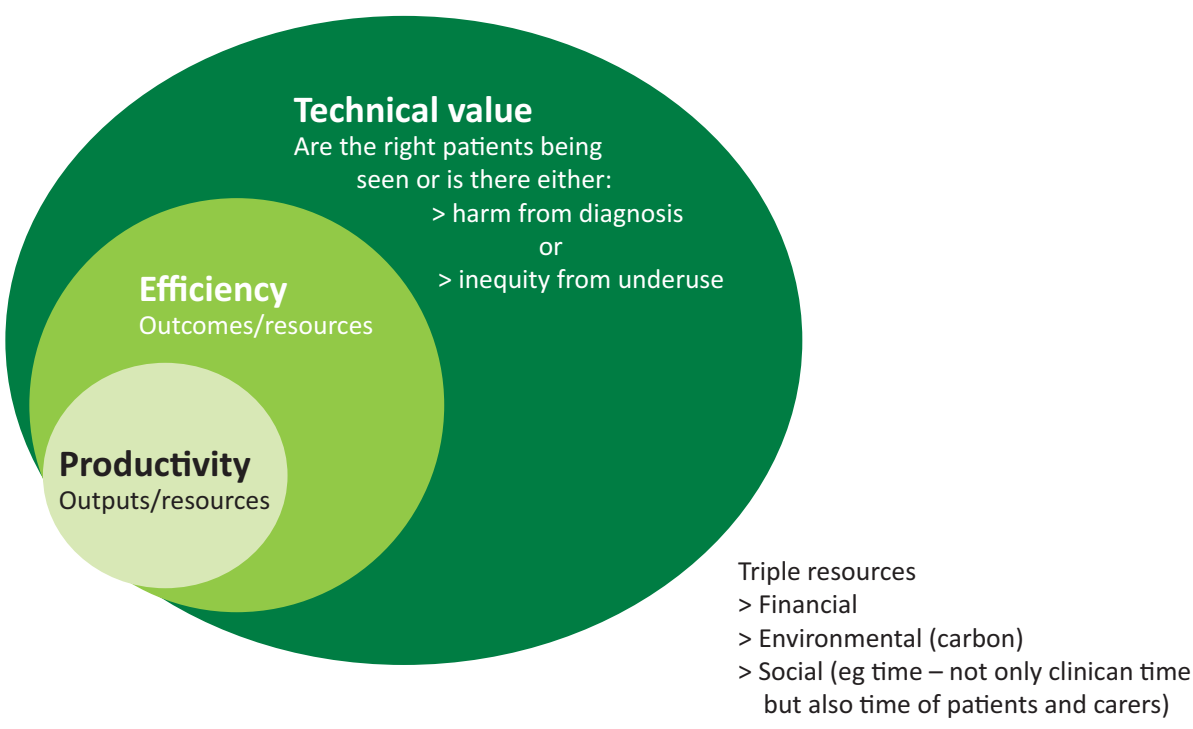

Fig 2. Productivity, efficiency and technical value (adapted with permission of M Gray, University of Oxford): Muir Gray et al. How to get better value healthcare. Offox press. ${ }^{8}$ well as daily living conditions (such as housing, air quality, diet and physical activity) and the impacts of destruction or depletion of natural environmental systems (causing, for example, soil erosion, droughts or flooding). ${ }^{3}$ In the UK, the Public Services (Social Value) Act 2012 obliges NHS bodies to consider how the services they commission and procure might improve the economic, social and environmental wellbeing of the area. The health service must balance its responsibility to meet immediate healthcare needs with the responsibility to actively promote health and prevent illness. At a minimum, services should seek to 'do no harm', ie minimise damage to the environmental, social and economic determinants of health caused by the delivery of care. Box 1 highlights the twin drivers for healthcare sustainability discussed in the paragraphs above: the practical and the ethical.

In fact, the goals of meeting immediate healthcare needs, conserving resources and promoting wider wellbeing are not necessarily in tension but may be mutually reinforcing, as highlighted in recent work by Nesta and the Health Foundation. Recognising that people need to feel connected to a thriving community as well as have their physical health needs addressed, they focus on person- and community-centred approaches to healthcare and present compelling evidence that these approaches lead to better outcomes and significant benefits for individuals, services and communities - estimating a $£ 950$ million saving per annum for the health service, with wider social savings

\section{Box 1. Why healthcare sustainability is important}

\section{The practical}

To ensure that the health service is able to continue to provide high quality care into the future, given the financial, social and environmental constraints that we are aware of.

\section{The ethical}

To protect the health of current and future generations by minimising the health service's contribution to climate change and its ongoing impact on determinants of health. eg employment outcomes, reduced social isolation, estimated at $£ 4.5$ billion. 6

\section{Redefining value}

Value in healthcare has been defined as outcomes relative to cost. ${ }^{7}$ As highlighted by Muir Gray, in the case of publicly funded health services, value is determined by how well the allocated resources are used to achieve outcomes not only for patients treated by a service but for all the people in need in the population. Therefore, achieving high value relies not just on maximising the efficiency with which interventions are delivered, but on avoiding underuse of high-value interventions in people with greater need and overuse of low-value interventions in people who will benefit less (Fig 2). ${ }^{8}$

A sustainability perspective extends thinking on value in two ways. Firstly, it broadens the scope of 'cost' or 'resources', considering patient and population outcomes against a 'triple bottom line' of environmental, social and economic costs or impacts (Figs 2 and 3). This is important, as it provides a consistent framework for measuring and driving sustainable improvements in care. Secondly, it requires limits on resource use in all three categories to be set at sustainable levels, since even an otherwise high-value service will not be sustainable if available resources are exceeded over time. Determining a sustainable level of resource use may need to be done at a macro level (eg national and international targets for carbon reduction), but to be meaningful will also need to be translated to the level at which services are managed (eg a carbon budget for asthma care in a local area). Such pathway-level limits have not yet been defined for environmental and social resources, but people engaged in improving services can nonetheless consider the current level of resource use and the impact of proposed changes.

\section{Value $=\frac{\text { Outcomes for patients and populations }}{\text { Environmental }+ \text { social + financial impacts }}$ (the 'triple bottom line')}

Fig 3. Sustainable value in healthcare. 
What does the inclusion of sustainability in quality and value mean for the process of quality improvement?

Gone are the days when patients were under the care of a single individual, whether physician, midwife or other. Healthcare is now a complex system with many staff and even organisations involved in the treatment of each person. Health professionals are therefore expected not only to provide excellent direct patient care, but to contribute to 'quality improvement', that is, the ongoing, systematic effort to improve patient outcomes and system performance. As a domain of quality, it follows that sustainability should be addressed as an integral part of quality improvement. Standard approaches to quality improvement will often enhance sustainability, through streamlining of processes and better targeting of clinical resources to achieve outcomes. However, explicit attention to all elements of the sustainable value equation will further highlight resource issues and encourage a more thoughtful and holistic approach to improving care for the whole population, hopefully driving progress towards a truly sustainable service.

In this section, we set out a simple approach for incorporating sustainability into mainstream quality improvement methodologies, which we have called the 'SusQI' framework. We identify four stages in the quality improvement process (setting goals, studying the system, designing the improvement effort and measuring impact) at which sustainability is usefully considered and make specific suggestions for its inclusion. The intention is to transform sustainability from a lofty aim into a practical component of everyday improvement efforts.

\section{The SusQI framework}

\section{Setting goals}

With finite resources available to deliver a high standard of patient care, quality improvement must look to maximise sustainable value, ie to deliver maximum health gain with minimum financial cost and harmful environmental impacts, while adding social value at every opportunity. A culture of resource stewardship is required, ensuring that the right care is provided to the right patient at the right time to achieve the outcomes that the patient values and avoiding cross-system waste.

Many clinical staff members are demotivated by pressures to meet financial constraints. They are being asked to reduce costs for their service without seeing the benefits passed on to their patients. Focusing on environmental and social impacts can provide a new motivation to join in improving pathways and processes.

\section{Studying the system}

A whole-systems view enables the full range of inputs and outputs to be recognised, highlighting wastes and potential assets that could otherwise be overlooked. In addition, understanding the scale of carbon reduction commitments may stimulate creative thinking and encourage people to more radically challenge the status quo.

A simple approach is to scan for environmental, social and economic resource use when mapping the current system. A good starting point for environmental costs are the 'carbon hotspots' for different care sectors described by the Sustainable Development Unit for NHS England and Public Health England, ${ }^{9}$ many of which can be surprising to practising clinicians (Fig 4$).{ }^{10}$

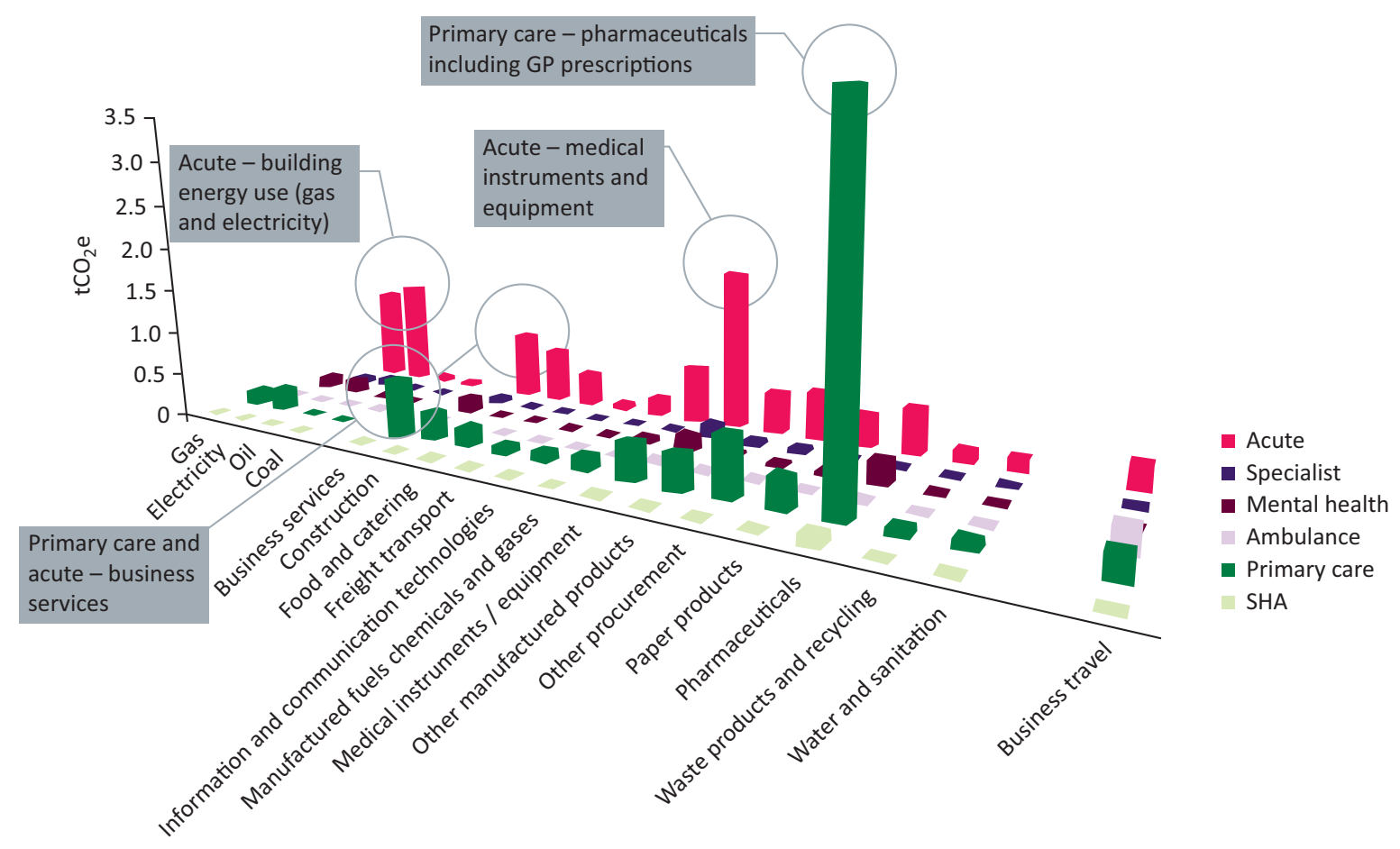

Fig 4. Goods and services carbon hotspots by healthcare sector. Source: Goods and services carbon hotspots. NHS Sustainable Development Unit, $2012 .{ }^{10}$ Reproduced with permission. SHA = strategic health authority 


\begin{tabular}{|c|c|}
\hline Financial & $\begin{array}{l}\text { Budget, incentives and finance, accounting } \\
\text { models that enable healthcare delivery }\end{array}$ \\
\hline Staff & Expertise, motivation and time \\
\hline Patients & $\begin{array}{l}\text { Commitment, skills, understanding and } \\
\text { confidence to look after their health, contribute } \\
\text { to treatments and initiate access to services } \\
\text { based on agreed thresholds or unforeseen needs }\end{array}$ \\
\hline Community & $\begin{array}{l}\text { Patients' social support networks that underpin } \\
\text { healthy, independent living such as families, } \\
\text { friends, charities, facilitated relationships with } \\
\text { support services and other patients }\end{array}$ \\
\hline $\begin{array}{l}\text { Staff } \\
\text { networks }\end{array}$ & $\begin{array}{l}\text { Connections between staff, experts in other } \\
\text { fields and patients that enable information } \\
\text { sharing and coordination of care }\end{array}$ \\
\hline Infrastructure & $\begin{array}{l}\text { From buildings and energy use, to equipment, } \\
\text { IT systems and local transport systems }\end{array}$ \\
\hline Natural & $\begin{array}{l}\text { Services provided by nature such as clean } \\
\text { air, fertile soil, stable climate, available } \\
\text { water, green space. Also, raw materials for } \\
\text { consumables eg metals, chemicals, fossil or } \\
\text { renewable fuels and biomaterials }\end{array}$ \\
\hline \multicolumn{2}{|c|}{$\begin{array}{l}\text { Source: Sustainable system-wide commissioning - guide for CCGs. Written and } \\
\text { researched by Forum for the Future, Centre for Sustainable Healthcare, NHS } \\
\text { Institute for Innovation and Improvement. NHS Institute for Innovation and } \\
\text { Improvement, March } 2013 \text { (reproduced with permission). }{ }^{11}\end{array}$} \\
\hline
\end{tabular}

Scanning for social resource use would consider the service's reliance (and impacts) on different groups, from patients and carers to staff, local communities and people working in the supply chain.

For an even more holistic view of the current system, a 'Seven Capitals Matrix ${ }^{\prime 11}$ can help identify the full range of resources that are being - or could be - used to deliver health improvement (Table 1).

\section{Design of the improvement effort}

The Centre for Sustainable Healthcare (CSH) has defined four principles of sustainable clinical practice, aiming to first minimise the need for healthcare activity and then reduce the environmental impact of activity that is retained, while maintaining or improving health outcomes. The principles are numbered in descending order of importance: 1) prevention, 2) patient empowerment and self-care, 3) lean systems and pathways, and 4) preferential use of technologies and interventions with lower environmental impact (Fig 5). A fifth, non-clinical principle calls for improved operational resource use, for example, reduced packaging or water consumption for a given procedure. ${ }^{12}$

Applying these principles systematically to the design of a quality improvement project should help to direct teams towards highest value improvements. Figure 6 shows a sample 'driver diagram' where the CSH principles have been used to identify and organise potential improvements to the respiratory inhaler prescribing.

\section{Measuring impact / measuring value}

Having redefined value (Fig 3) and modified the original goal of quality improvement to include environmental and social dimensions, the evaluation of quality improvement initiatives should ensure that impacts in these areas are captured, alongside health outcomes and financial costs (see Mortimer et al in this issue. ${ }^{13}$ Traditionally, these impacts (eg benefits to staff wellbeing, time savings or reduced fuel and parking charges from avoided patient journeys) may have been excluded from cost-benefit analyses.

\section{Embedding sustainability into everyday practice}

To truly embrace sustainability into the healthcare culture we need to work towards including it in the education and training of healthcare professionals. Embedding the principles of sustainability in our education will normalise a culture of resource stewardship, wider thinking and planning for the future. The General Medical Council (GMC) recognises 'demonstrating the knowledge and skills to improve the sustainability of health systems' as one of three overarching learning outcomes for

\begin{tabular}{|c|c|}
\hline $\begin{array}{l}\text { Patient empowerment and } \\
\text { self-care } \\
\text { Support patients to take a bigger } \\
\text { role in managing their own health } \\
\text { and healthcare }\end{array}$ & $\begin{array}{l}\text { Prevention } \\
\text { > Promoting health } \\
>\text { Preventing disease } \\
\text { > Reduce the need for } \\
\text { healthcare }\end{array}$ \\
\hline $\begin{array}{l}\text { Lean service delivery } \\
\text { > Services where people need } \\
\text { them } \\
\text { > Streamlining care to minimise } \\
\text { low value activity }\end{array}$ & $\begin{array}{l}\text { Low carbon alternatives } \\
\text { > Preferential use of effective } \\
\text { treatment and medical } \\
\text { technologies with lower } \\
\text { environmental impact } \\
\text { > Minimising waste of medications, } \\
\text { consumables and energy }\end{array}$ \\
\hline
\end{tabular}

Fig 5. The Centre for Sustainable Healthcare 'Principles of sustainable clinical practice'. ${ }^{12}$ 

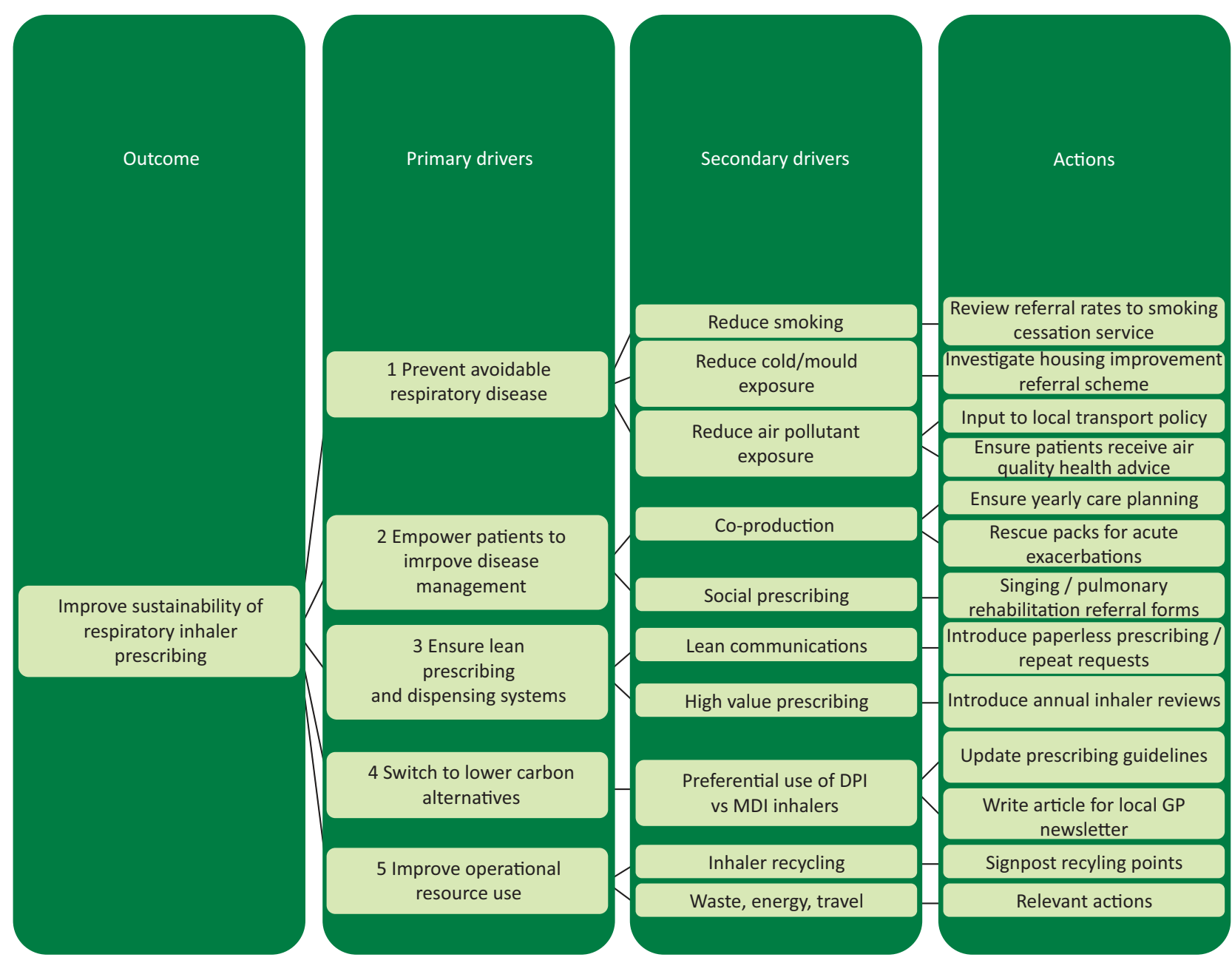

Fig 6. Driver diagram illustrating use of The Centre for Sustainable Healthcare principles of sustainable clinical practice.

sustainability in medical education, ${ }^{14}$ referenced in their Outcomes for graduates document.

Recent reports such as the National Quality Board's Shared commitment to quality ${ }^{15}$ recognise sustainability as a domain of quality and reinforce the need to focus on building workforce capability to improve quality. Developing capability in quality improvement is integral to the new GMC Generic Professional Capabilities Framework, ${ }^{16}$ launched in May 2017, to the NHS Improvement Developing People - Improving Care ${ }^{17}$ national framework on improvement and leadership development and to the Academy of Medical Royal Colleges Quality improvement; training for better outcomes report. ${ }^{18}$ This is a tipping point in healthcare education with significant opportunity to influence how these recommendations are effectively implemented for the highest value impact.

Table 2 summarises how our proposed modifications could be included within standard quality improvement training and practice, highlighting the intended benefits at each stage. This provides a practical framework for the development of tools and learning resources which could be incorporated across mainstream training programmes - an approach that we are currently piloting in undergraduate and postgraduate settings in the UK.

The ideal quality improvement project might apply all four principles of sustainable practice to achieve measurable positive outcomes for patients and the triple bottom line. Currently, most projects already apply at least one of the principles, and encouraging teams to retrospectively evaluate their project using the SusQI framework (Supplementary file 1 [Case study 1]) could reinforce sustainable approaches and raise awareness of the new model.

Professional bodies and educational institutions could further encourage adoption of SusQI, for example by introducing new sustainability categories and awards at healthcare conferences and in journals, or through adaptation of existing quality improvement / leadership development programmes such as 'RCP Quality Improvement ${ }^{19}$ and the RCP Chief Registrar scheme. ${ }^{20}$ Already, medical royal colleges such as the RCP and the Royal College of Psychiatrists are offering clinical fellows and scholars the opportunity to work at a regional and national level to study services and suggest and implement more sustainable practices. Finally, there is a need for research to identify the most effective approaches to incorporating sustainability into quality improvement practice and to evaluate the impact on the outcomes achieved.

\section{Conclusion}

Sustainability is an important and legitimate domain of quality in healthcare, which calls for the redefinition of value to incorporate social and environmental costs. 
Table 2. Building sustainability into quality improvement ('SusQI'): intended benefits

\begin{tabular}{|c|c|c|}
\hline QI element & Sustainability content & Intended benefits \\
\hline 1 Setting goals & Sustainability as a domain of quality; relationship to other domains & $\begin{array}{l}\text { New motivation to contribute to QI, energy } \\
\text { for change }\end{array}$ \\
\hline $\begin{array}{l}2 \text { Studying the } \\
\text { system }\end{array}$ & $\begin{array}{l}\text { Understanding environmental and social resource use / impacts; } \\
\text { carbon hotspots in the NHS; 'seven capitals' matrix }\end{array}$ & $\begin{array}{l}\text { Highlights wastes and opportunities which } \\
\text { are often overlooked; stimulates radical } \\
\text { thinking }\end{array}$ \\
\hline $\begin{array}{l}3 \text { Designing the } \\
\text { improvement } \\
\text { effort }\end{array}$ & $\begin{array}{l}\text { The Centre for Sustainable Healthcare principles of sustainable } \\
\text { clinical practice (prevention, patient empowerment and self-care, } \\
\text { lean systems, low carbon alternatives) }{ }^{a} \text { - drivers and process changes }\end{array}$ & $\begin{array}{l}\text { Directs towards highest value } \\
\text { improvements, future proofing }\end{array}$ \\
\hline $\begin{array}{l}4 \text { Measuring } \\
\text { impact / return on } \\
\text { investment }\end{array}$ & Triple bottom line / sustainable value equation; measuring carbon & $\begin{array}{l}\text { Drives sustainable change; allows benefits to } \\
\text { be communicated to broader audience, not } \\
\text { exclusively regarding financial cost-benefit }\end{array}$ \\
\hline
\end{tabular}

Including the concept of sustainability and resource stewardship as part of quality improvement provides a practical way for healthcare professionals to respond to ethical challenges such as climate change and social inequalities, to which we all contribute through our use of resources, and which present an urgent and unequal threat to vulnerable communities worldwide.

A sustainability lens may also bring immediate benefits to quality improvement, including new motivation and energy for change, highlighting wastes and opportunities otherwise overlooked, encouraging whole-systems thinking and directing projects systematically towards the highest value improvements.

We propose a practical framework for embedding sustainability across quality improvement education, practice and research.

\section{What this paper offers}

$>$ A longer-term perspective on the responsibilities of health services and professionals.

> A holistic approach to defining value, which considers environmental and social impacts alongside patient-based outcomes and financial costs.

$>$ A practical and ethical solution to address the sustainability of healthcare.

\section{Author contributions}

FM was main author and led on conception, design, data analysis and drafting. JI contributed to the design and drafting of this manuscript. AW contributed to data acquisition and analysis, drafting and critical review. EV contributed to design and critical review. All authors gave final approval of the manuscript and agreement to accountability.

\section{Supplementary material}

Additional supplementary material may be found in the online version of this article at http://futurehospital.rcpjournal.org:

S1 - Case study 1: retrospective sustainability review of a hospitalbased QI project on smoking cessation.

\section{References}

1 Royal College of Physicians. A strategy for quality: 2011 and beyond. London: RCP, 2011.

2 Atkinson S, Ingham J, Cheshire M, Went S. Defining quality and quality improvement. Clin Med 2010;10:537-9.
3 World Health Organization. Closing the gap in a generation: health equity through action on the social determinants of health - final report. Geneva: WHO, 2008.

4 World Health Organization and the Calouste Gulbenkian Foundation. Social determinants of mental health. Geneva: WHO, 2014.

5 Royal College of Physicians. How doctors can close the gap. Tackling the social determinants of health through culture change, advocacy and education. London: RCP, 2010.

6 Wood S, Finnis A, Khan H, Ejbye J. At the heart of health: Realising the value of people and communities. London: Nesta, 2016.

7 Porter ME. What is value in health care? N Engl J Med 2010;363:2477-81.

8 Gray M. How to get better value healthcare, 2nd edn. Oxford: Offox Press, 2011.

9 Sustainable Development Unit. Carbon update for the health and care sector in England 2015. Cambridge: SDU, 2016.

10 NHS Sustainable Development Unit. Goods and services carbon hotspots. SDU, 2012. www.sduhealth.org.uk/documents/resources/ Hotspot full.pdf

11 Forum for the Future, Centre for Sustainable Healthcare, NHS Institute for Innovation and Improvement. Sustainable System-Wide Commissioning - Guide for CCGs. NHS Institute for Innovation and Improvement, 2013.

12 Mortimer F. The sustainable physician. Clin Med 2010;10:110-11.

13 Mortimer F, Isherwood J, Kenward C, Pearce M, Vaux E. Sustainability in quality improvement: measuring impact. Clin Med 2018;18:94-7.

14 Thompson T, Walpole S, Braithwaite I et al. Learning objectives for sustainable health care. Lancet 2014;384:1924-5.

15 National Quality Board. Shared commitment to quality. NHS England, 2016. www.england.nhs.uk/publication/shared-commitment-toquality-from-nqb/

16 General Medical Council. Generic Professional Capabilities Framework. GMC, 2017.

17 NHS Improvement and Leadership Development Board. Developing People - Improving Care. A national framework for action on improvement and leadership development in NHS-funded services. NHS Improvement, 2016.

18 Academy of Medical Royal Colleges. Quality Improvement training for better outcomes. London, AOMRC, 2016.

19 Royal College of Physicians. RCP Quality Improvement (RCPQI). London: RCP, 2017. www.rcplondon.ac.uk/projects/rcp-quality-improvement-rcpqi

20 Royal College of Physicians. RCP chief registrar scheme. www.rcplondon. ac.uk/projects/rcp-chief-registrar-scheme. [Accessed 26 April 2018.]

Address for correspondence: Dr Frances Mortimer, Centre for Sustainable Healthcare, 287-291 Banbury Road, Oxford OX2 7JQ, UK.

Email: frances.mortimer@sustainablehealthcare.org.uk 